Magazine of Concrete Research Volume 68 Issue 21

Mechanical properties and behaviour of concrete reinforced with spiral-shaped steel fibres under dynamic splitting tension

$\mathrm{HaO}$ and Hao

\title{
Mechanical properties and behaviour of concrete reinforced with spiral-shaped steel fibres under dynamic splitting tension
}

\section{Yifei Hao}

Tianjin University and Curtin University Joint Research Center of Structural Monitoring and Protection, Centre for Infrastructural Monitoring and Protection, School of Civil and Mechanical Engineering, Curtin University, Bentley, Australia (corresponding author: hao.yifei@outlook.com)

\section{Hong Hao}

Tianjin University and Curtin University Joint Research Center of Structura Monitoring and Protection, Centre for Infrastructural Monitoring and Protection, School of Civil and Mechanical Engineering, Curtin University, Bentley, Australia

Concrete exhibits excellent resistance to compressive forces, but is brittle and weak in tension. Various types of fibres have been investigated by many researchers to improve the ductility and energy absorption capability of concrete materials and structures under static and blast and impact loadings. Spiral-shaped steel fibres were recently proposed as reinforcement in a concrete matrix and it was found that spiral fibre reinforcement can significantly improve the ductility, crack control ability and energy absorption capacity of concrete material under static and impact compressive loads. This paper presents an experimental study of the static and dynamic properties of steel fibre reinforced concrete (SFRC) materials under splitting tension. SFRC materials mixed with spiral-shaped steel fibres of different volume fractions were prepared and tested. A high-speed camera was used to capture the deformation, failure and crack opening process of the tested specimens. The contribution of spiral fibres to the mechanical properties and behaviour of concrete at high strain rate under splitting tension was investigated. Analyses of the test results revealed the effectiveness of spiral fibres in improving the performance of SFRC (e.g. crack control, energy absorption capability and more pronounced rate sensitivity under dynamic splitting loading). Moreover, crack opening and closing (pull-back by spiral fibres) processes were observed, demonstrating the excellent bonding and outstanding performance of spiral steel fibres in maintaining the integrity of the concrete material, thus resulting in significant improvements in impact resistance and energy dissipation.

\section{Notation}

$b \quad$ width of load-bearing strip

$D \quad$ diameter of specimen

E Young's modulus of specimen

$f_{\mathrm{td}} \quad$ peak dynamic splitting tensile stress

$L \quad$ length of specimen

$P \quad$ compressive load in quasi-static test

$P_{\mathrm{T}} \quad$ transmitted force in split Hopkinson pressure bar (SHPB) test

$R \quad$ radius of SHPB pressure bar

$t \quad$ time lag between start of transmitted stress wave and maximum transmitted stress

strain rate

quasi-static splitting tensile strength

loading rate

incident stress

stress wave at incident end of specimen in SHPB tests

\section{$\sigma_{\mathrm{R}} \quad$ reflected stress \\ $\sigma_{\mathrm{T}} \quad$ transmitted stress}

\section{Introduction}

Concrete is the most consumed construction material in the world due to its widely available constituents, ease of being moulded to shape in the fresh state and impressive resistance to compressive loads. However, as a brittle material, concrete has a very limited strain capacity and low resistance to tension/ bending, and thus energy absorption capability. To overcome such weaknesses, short discrete fibres (e.g. natural, glass, synthetic and steel fibres) have been used to reinforce concrete and subsequent improvements in the mechanical properties of fibre reinforced concrete materials have been widely investigated (Brandt, 2008). Steel fibre reinforced concrete (SFRC) is regarded by researchers and engineers as a largely superior construction material in comparison with ordinary concrete, 
and has been commonly used to build high-rise, long-span structures and critical structures with special requirements to resist blast and impact loads. Many types of steel fibres (e.g. hooked-end, crimped, twisted, enlarged-end and undulated fibres) have been investigated and are commercially available.

Compared with its relatively insignificant contribution to compressive strength, the addition of steel fibres produces marked improvements in tensile strength, ductility and post-cracking behaviour by crack bridging, and provides resistance to the opening of cracks (Abadel et al., 2015; Hao et al., 2016; Yoo et al., 2015). Understanding the bond characteristics between steel fibres and a concrete matrix is essential to analyse the mechanical properties of SFRC in tension. Comprehensive studies on the pull-out behaviour and bond-slip relations of steel fibres on a cementitious matrix have been conducted (Alwan et al., 1999; Laranjeira et al., 2010a, 2010b; Naaman and Najm, 1991; Naaman and Shah, 1976; Naaman et al., 1991; Robins et al., 2002; Zīle and Zīle, 2013). It is generally agreed that the combined action of bond components (e.g. adhesion between fibres and matrix, the geometry of the steel fibres, the interlocking mechanism among fibres, and the bond component due to friction) dominates the resistance of individual fibres to pull-out, thus affecting the mechanical properties of SFRC materials (Naaman and Najm, 1991). However, the commercially-produced steel fibres available in the market and those considered in most previous experimental studies are only able to provide anchorage and a frictional bond along one or two directions in a two-dimensional (2D) plane. Spiralshaped steel fibres were investigated in a recent study by $\mathrm{Xu}$ et al. (2012b), who demonstrated that, unlike other deformed fibres, a spiral fibre had a 3D anchorage bond in the concrete matrix due to the fibre shape and a better mechanical component of bond due to fibre deformation, as illustrated in Figure 1.
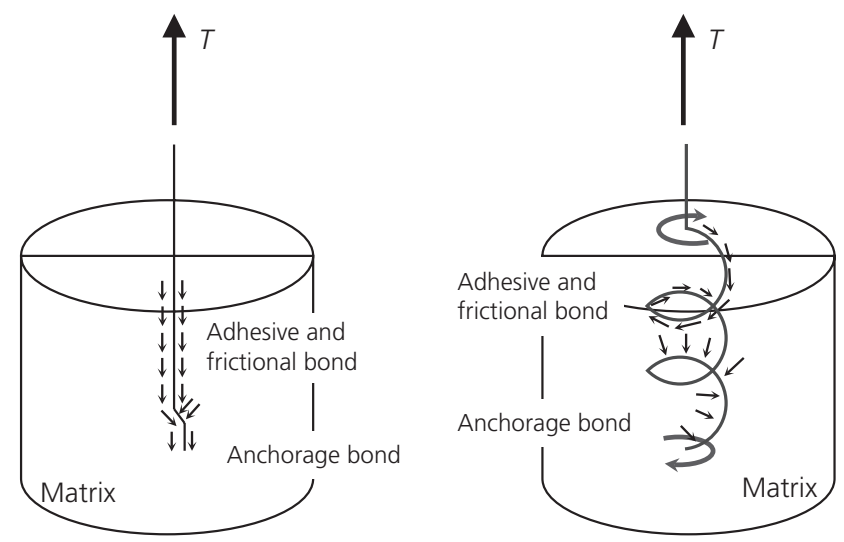

Figure 1. Anchorage bond and frictional bond between fibres and concrete matrix (not to scale)
During their service life, concrete structures may be subjected to high-rate loadings as a result of an accidental explosion, natural hazard or vehicle impact. For design and analysis of SFRC structures against blast and impact loads, understanding the dynamic behaviour and properties of SFRC materials is essential. It is worth mentioning that, under dynamic compression, concrete reinforced with hooked-end steel fibres was reported not to exhibit a significant increase in uniaxial compressive strength although it possessed better post-peak ductility than plain concrete, but the post-peak ductility was absent at strain rates higher than $50 \mathrm{~s}^{-1}$ because fragments of concrete were no longer able to bond onto the steel fibres (Lok and Zhao, 2004). With a 3D anchorage bond and a better mechanical bond component due to the shape and stretching capability of spiral steel fibres, the fibre addition is expected to contribute more significantly to the impact resistance, deformability/ductility and energy absorption capability of SFRC materials and structures. Drop-weight impact tests on concrete specimens reinforced with $1 \%$ spiral steel fibres demonstrated significantly improved mechanical properties in terms of the impact loading resistance capacity, ultimate compressive strength, post-failure strength and energy absorption capability (Xu et al., 2012b). Prominent bonding, ductility and toughness of SFRC with $1 \%$ spiral fibres in splitting tension under dropweight impact have also been demonstrated (Xu et al., 2012a). Cylindrical specimens $(\varnothing 100 \times 100 \mathrm{~mm})$ with the inclusion of $1 \%$ fibres were tested using an instrumented drop-weight system by Xu et al., (2012a). For better control and prediction of splitting cracks, $18 \mathrm{~mm}$ triangular notches were added. The existence of notches results in stress concentration and strength reduction when compared with a cylindrical specimen without a notch, so an adjusting factor derived from static tests was used. Although this approach enabled better control of crack initiation and development, whether the adjusting factor was independent of the loading rate was not demonstrated. Therefore, the test results - especially the splitting tensile strength of the specimens - presented by Xu et al. (2012a) under high-rate loads using a factor that was derived from static tests need to be further verified.

Split Hopkinson pressure bar (SHPB) tests of dynamic compressive properties at different strain rates of spiral fibre reinforced concrete material were reported by $\mathrm{Hao}$ and $\mathrm{HaO}$ (2013). The present study extends the work reported by Hao and Hao (2013) and Xu et al. (2012a), and further investigates the behaviour of SFRC material mixed with spiral fibres of different volumetric dosages under quasi-static and dynamic splitting tension using an SHPB testing system.

\section{Experimental programme}

\section{Selection of testing methods}

For determining the quasi-static tensile properties of SFRC materials, it is generally agreed that it is difficult to apply a pure tension force free of eccentricity in a direct tensile test. 
When the specimen is anchored by grips, compression from the grips is combined with tension from the testing machine, and the distribution of compressive stress is dependent on the geometrical factors of the specimen. The combined force has been shown to lead to failure or fracture at stress levels below either the maximum tensile or compressive strength (Kupfer et al., 1969). While some researchers have strived to conquer these difficulties and develop a direct tensile testing method with eliminated/minimised influence from gripping devices and eccentricity (Graybeal and Baby, 2013; Swaddiwudhipong et al., 2003; Zheng et al., 2001), ASTM has given recommendations to determine the quasi-static tensile properties by conducting third-point bending tests on SFRC beam specimens with or without a notch at the mid-span (ASTM, 2006). The fib Model Code recommends conducting three-point bending tests on notched beam specimens and using reverse calculation to determine the tensile properties of SFRC materials (Taerwe and Matthys, 2013). However, flexural tests tend to overestimate the strength by assuming a linear stress distribution along the cross-section. Moreover, in high-speed dynamic tests, inertia resistance from a beam specimen is large and difficult to quantify, which makes accurate determination of the material strength difficult. Attempts have also been made to justify the applicability of splitting tension to determine the tensile strength of SFRC materials; however, this testing method does not provide suitable data for post-cracking behaviour (Denneman et al., 2011).

Numerous studies have indicated that the strengths of cementitious materials are strain rate dependent; that is, the strength increases with strain rate (Bischoff and Perry, 1991; Cotsovos and Pavlović, 2008; Hao et al., 2013; Malvar and Ross, 1998). SFRC material is no exception, since the strength of the concrete matrix is dependent on strain rate and the loading rate influences the pull-out behaviour of steel fibres from the matrix (Banthia and Trottier, 1991; Kim et al., 2009). The strain rate dependency of SFRC has been observed in many studies using different testing methods (Hao and Hao, 2013; Lok and Zhao, 2004; Xu et al., 2012a, 2012b). The ratio of dynamic to quasi-static strengths, termed the dynamic increase factor (DIF), is widely used to describe a material's strength increment at high strain rate in numerical models. The fib Model Code suggests DIF versus strain rate relations for plain concrete material that can be used in design and analysis of structures subjected to blast and impact load (Taerwe and Matthys, 2013). Although the splitting tensile test does not give reliable post-cracking data, the derived strengths are more consistent than those determined by direct tensile and bending tests (Davies and Bose, 1968). Due to the consistent results and ease of implementation for conducting SHPB tests, splitting tensile tests were adopted in the experimental programme described here as the primary aim of the study was to derive tensile DIF relations of SFRC material with spiral fibres.

\section{Preparation of specimens}

The spiral steel fibre used to reinforce concrete is shown in Figure 2. The fibres were fabricated by coiling steel wires and being cut into short lengths, and they were loosely presented. Different volume fractions of fibres - namely $0.0 \%$ (plain concrete), $0 \cdot 5 \%, 1 \cdot 0 \%$ and $1 \cdot 5 \%$ - were used to prepare specimens to investigate the influence of fibre volume fraction. The nominal length of each spiral fibre was $15 \mathrm{~mm}$ while the diameter of the wire was $0.56 \mathrm{~mm}$, giving an aspect ratio (length to diameter) of 27. The strength and geometric dimensions of the fibres are summarised in Table 1. Ideally, the specimen size should be around three times the size of each constituent in a composite material. The reasons for selecting the fibre and specimen sizes were as follows.

- If the specimen size was too large, it was very difficult to achieve stress uniformity under dynamic impact loading and the material properties at relatively high strain rate could not be obtained.

- If the fibre length was too short, its effectiveness in increasing the material ductility, post-yield crack stopping and so on could not be fully achieved.

The specimen size was thus chosen to be $2 \cdot 5$ times larger than the fibre size - a compromise for achieving higher strain rates in the tests. The strength of the spiral fibre was $1300 \mathrm{MPa}$. The cement used in the present study was ordinary Portland cement grade 33 with a density of $3.15 \mathrm{~g} / \mathrm{cm}^{3}$ and minimum compressive strength of $33 \mathrm{MPa}$ after $28 \mathrm{~d}$ of curing. Details of the mixture proportions are listed in Table 2.

To avoid balling and achieve good dispersion in the concrete mix, individual fibres were continuously dosed to the fluid mix, as suggested by Shah et al. (1993). The spiral shape made the individual fibres less movable when mixing them in the concrete and therefore balling was less likely. The mixes were placed into $\varnothing 75 \times 500 \mathrm{~mm}$ PVC tubes and cured for $28 \mathrm{~d}$. The concrete specimens were then cut into $\varnothing 75 \times 37.5 \mathrm{~mm}$ cylinders, smoothed at both ends, dried and tested. In the present study, 69 specimens were tested -12 specimens for

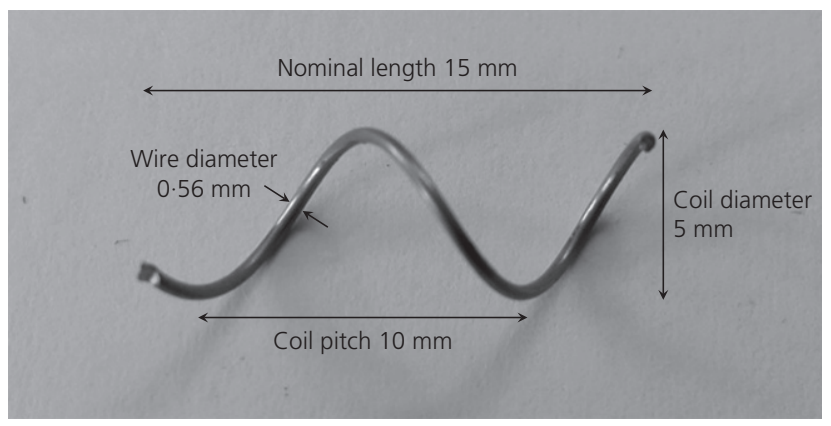

Figure 2. Spiral steel fibre 
Table 1. Specifications of spiral steel fibres

\begin{tabular}{|c|c|c|c|c|c|c|c|c|}
\hline \multirow[t]{2}{*}{ Mix } & \multirow[t]{2}{*}{$w / c$} & \multirow[t]{2}{*}{$V_{f}$} & \multicolumn{6}{|c|}{ Mix proportion: $\mathrm{kg} / \mathrm{m}^{3}$} \\
\hline & & & Water & Cement & $10 \mathrm{~mm}$ aggregate & $7 \mathrm{~mm}$ aggregate & $<4 \mathrm{~mm}$ aggregate & Sand \\
\hline Plain concrete & 0.48 & - & 205 & 426 & 444 & 306 & 130 & 843 \\
\hline $0.5 \%$ & 0.48 & $0.5 \%$ & 205 & 426 & 444 & 306 & 130 & 843 \\
\hline $1.0 \%$ & 0.48 & $1.0 \%$ & 205 & 426 & 444 & 306 & 130 & 843 \\
\hline $1 \cdot 5 \%$ & 0.48 & $1.5 \%$ & 205 & 426 & 444 & 306 & 130 & 843 \\
\hline
\end{tabular}

Table 2. Mixture proportions ( $\mathrm{W} / \mathrm{C}$, water to cement ratio; $V_{\mathrm{f}}$ volume fraction of fibres)

quasi-static splitting tensile tests and 57 specimens for dynamic splitting tensile tests with the SHPB apparatus.

\section{Quasi-static tests}

The quasi-static splitting tensile tests were conducted using a Baldwin hydraulic machine. The test setup for specimens under splitting tensile loads is illustrated in Figure 3. The tests were carried out at a loading rate of $0 \cdot 1 \mathrm{MPa} / \mathrm{s}$. While the applied vertical load was recorded, two linear variable differential transducers (LVDTs), placed on either side of the tested specimen, recorded the lateral deformation. The combination of the recorded deformation from each side was used to represent the lateral deformation capacity (LDC). The strengths were obtained from testing the $75 \mathrm{~mm}$ diameter specimens, instead of the $100 \mathrm{~mm}$ diameter specimens suggested by ASTM (ASTM, 2011). The reason for using the same specimen size in both static and dynamic tests was to maintain consistency in order to derive more reliable dynamic material

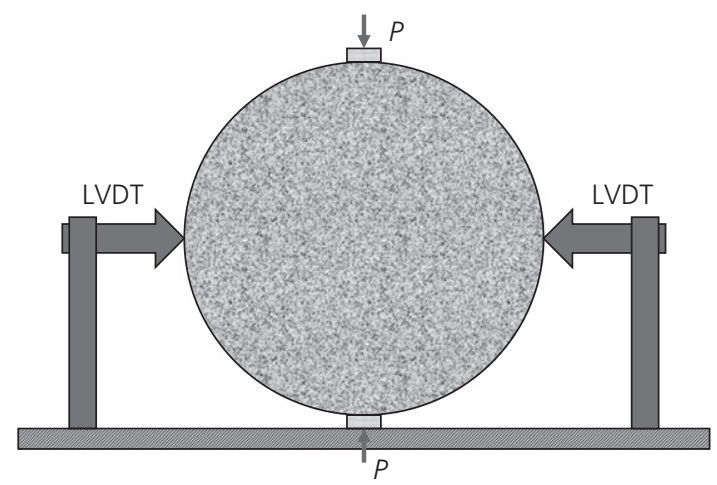

Figure 3. Schematic view of quasi-static splitting tensile test setup properties such as the DIF (the ratio of dynamic strength to static strength). Using the same specimen size in both static and dynamic tests is a common approach in testing dynamic material properties (e.g. Hao et al., 2013; Ross et al., 1995).

\section{Dynamic splitting tensile tests}

The dynamic splitting tensile tests were conducted using the SHPB test system. The test system, including the SHPB setup and the data acquisition system, is shown in Figure 4. Both pressure bars had the same dimensions of $\varnothing 75 \times 2000 \mathrm{~mm}$ and the absorption bar was of size $\varnothing 75 \times 1000 \mathrm{~mm}$. Strain gauges were glued to the middle surface of the pressure bars. The bars were made of stainless steel with a Young's modulus of $200 \mathrm{GPa}$, density of $7800 \mathrm{~kg} / \mathrm{m}^{3}$, elastic wave velocity of $5064 \mathrm{~m} / \mathrm{s}$ and Poisson's ratio of $0 \cdot 3$. A tapered impact ram, as proposed by Lok et al. (2002) was used as the striker bar. Using such a projectile has been demonstrated to be able to initiate a half-sine loading waveform (as noted in the section 'Stress uniformity and strain rate estimation'), and can eliminate violent wave oscillation and dispersion in SHPB tests with large-diameter pressure bars. Moreover, it permitted a significant reduction in the length of the input bar. To capture the failure processes of the specimens, a high-speed video camera operating at up to one frame per microsecond (1 million frames per second) was used in the test.

\section{Observations and test results}

\section{Results of quasi-static tests}

The quasi-static splitting test results are briefly discussed elsewhere (Hao and Hao, 2013). Since they were used as the reference to derive the tensile DIF in this study, the test results are also reported here. 


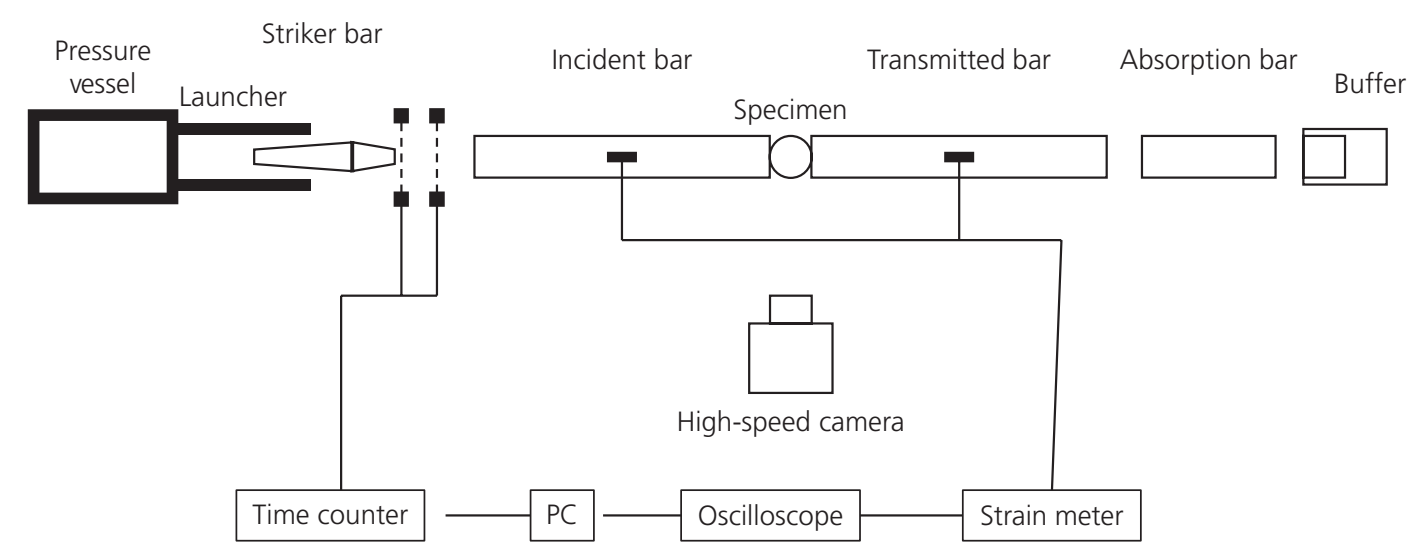

Figure 4. SHPB test system

Equation 1 is used to calculate the quasi-static splitting tensile strength $(\sigma)$ of specimens with applied vertical compressive load $P$ (Tang, 1994).

1. $\sigma=\frac{2 P}{\pi L D}\left[1-\left(\frac{b}{D}\right)^{2}\right]^{3 / 2}$

where $L$ is the length of the specimen, $D$ is the specimen diameter and $b$ is the width of the load-bearing strip.

Inter-granular fracture was observed in the static splitting tests. Combined with records from the LVDTs, the force-LDC curves are compared in Figure 5. It can be seen that stretching the spiral fibres allowed large displacement of the specimen. During the tests it was found that although the fibres were stretched, the bonding between the fibre segments still buried in the concrete mix was still very strong and the specimen's integrity was maintained to some extent. With the

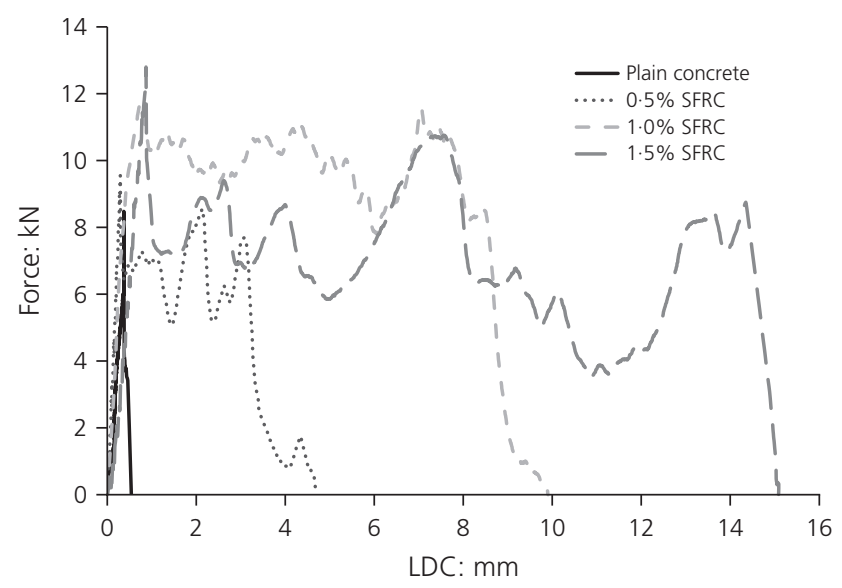

Figure 5. Quasi-static splitting tensile stress versus LDC for different specimens development of cracks, fibres in the top section were either pulled out or fractured while fibres in the bottom section started to be stretched and provided further support to maintain the specimen integrity. Besides the fibres' strong bonding, which contributed to the post-crack resistance, it was likely that the fibres maintained the specimen integrity so that the load could still be transferred by the split halves through the fibres as shown in Figure 6. The load-transfer mechanism through the fibres made the fibre-dosed specimens able to dissipate much more energy than plain concrete. The capability of keeping the integrity, and thus the higher energy dissipation, was found to increase with fibre dosage.

The average splitting tensile strength of the plain concrete specimens without fibre reinforcement was the lowest (2.02 MPa). The tensile strengths of SFRC specimens with volume fractions of spiral fibres of $0 \cdot 5 \%, 1 \cdot 0 \%$ and $1.5 \%$ were 2.37 MPa, 2.87 MPa and 2.98 $\mathrm{MPa}$, which are respectively $17 \%, 42 \%$ and $48 \%$ higher than the plain concrete splitting tensile strength. Moreover, the energy dissipated by the SFRC specimens was much more significant than that by the plain concrete due to the markedly enhanced deformability. Ultimately, in the present study, the energy dissipated by the

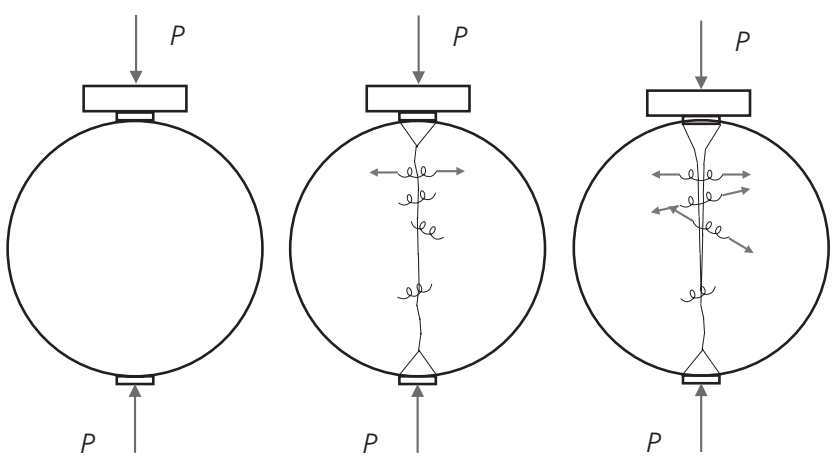

Figure 6. Illustration of load-transfer mechanism 
$1 \cdot 5 \%$ SFRC specimen was more than 60 times that of the plain concrete specimen. The material properties under quasi-static splitting tension are summarised in Table 3, in which all the data are averaged values from tests on three specimens of each type. It was observed that, under a well-controlled laboratory environment for specimen preparation, the largest discrepancy between the mean and individual strengths varied from $3 \%$ to $6 \%$ for specimens tested for each case, as shown in Table 4. The discrepancies were therefore in an acceptable range and the static tests gave reliable and consistent results. Nonetheless, further statistical analysis of the SFRC material properties accounting for the random distribution of aggregates and fibres, which requires a large number of experimental and numerical tests, is suggested for a more comprehensive understanding of the statistical variations of material properties.

\section{Results of dynamic splitting tensile tests}

\section{Stress uniformity and strain rate estimation}

In SHPB tests, with the absence of load-bearing strips and the assumption that the peak dynamic stress $\left(f_{\mathrm{td}}\right)$ of the splitting cylinder is proportional to the peak transmitted stress $\left(\sigma_{\mathrm{T}}\right)$, Equation 1 can be modified as (Tedesco and Ross, 1993)

2. $f_{\mathrm{td}}=\frac{2 P_{\mathrm{T}}}{\pi L D}$

in which

3. $P_{\mathrm{T}}=\pi R^{2} \sigma_{\mathrm{T}}$

is the transmitted force and $R$ is the radius of the SHPB pressure bar.
Accordingly, the loading rate $(\dot{\sigma})$ and strain rate $(\dot{\varepsilon})$ in the specimen can be estimated from

4. $\dot{\sigma}=\frac{f_{\mathrm{td}}}{t}$

and

5. $\dot{\varepsilon}=\frac{\dot{\sigma}}{E}$

where $t$ is the time lag between the start of the transmitted stress wave and the maximum transmitted stress and $E$ is the Young's modulus of the specimen.

For the validity of SHPB tests, as well as Equations 3-5, the stress uniformity in the specimen is essential. To obtain the stress wave at the incident end of the specimen in SHPB tests, Equation 6 needs be used and compared with the stress wave at the transmitted end of the specimen to check the equilibrium of stress

\section{6. $\sigma_{\mathrm{IS}}=\sigma_{\mathrm{I}}+\sigma_{\mathrm{R}}$}

in which the stress at the incident end of the specimen is denoted by $\sigma_{\mathrm{IS}}$ and incident and reflected stresses are represented by $\sigma_{\mathrm{I}}$ and $\sigma_{\mathrm{R}}$, respectively.

Typical stress histories in the SHPB tests are shown in Figure 7(a), while a comparison of $\sigma_{\mathrm{IS}}$ and $\sigma_{\mathrm{T}}$ is given in Figure 7(b). As shown in Figure 7(b), the difference between $\sigma_{\mathrm{IS}}$ and $\sigma_{\mathrm{T}}$ is negligible, indicating the validity of the SHPB test results reported in the present study.

\begin{tabular}{lccr}
\hline Material & Dry density: $\mathrm{kg} / \mathrm{m}^{3}$ & Tensile strength: MPa & Energy dissipated: J \\
\hline Plain concrete & 2201 & 2.02 & 1.6 \\
$0.5 \%$ SFRC & 2229 & 2.37 & 23.2 \\
$1.0 \%$ SFRC & 2247 & $2 \cdot 87$ & 85.4 \\
$1.5 \%$ SFRC & 2286 & 2.98 & $103 \cdot 1$
\end{tabular}

Table 3. Averaged properties and energy dissipation

\begin{tabular}{lccccc}
\hline Material & \multicolumn{3}{c}{ Strength: MPa } & Standard deviation & Coefficient of variation \\
\hline Plain concrete & 1.97 & 2.04 & 2.06 & 0.039 & 0.019 \\
$0.5 \%$ SFRC & 2.31 & 2.39 & 2.42 & 0.047 & 0.020 \\
$1.0 \%$ SFRC & 2.77 & 2.91 & 2.92 & 0.068 & 0.024 \\
$1.5 \%$ SFRC & 2.87 & 3.02 & 3.05 & 0.079 & 0.027
\end{tabular}

Table 4. Material properties obtained from quasi-static tests 
Mechanical properties and behaviour of concrete reinforced with spiral-shaped steel fibres under dynamic splitting tension

$\mathrm{HaO}$ and $\mathrm{HaO}$

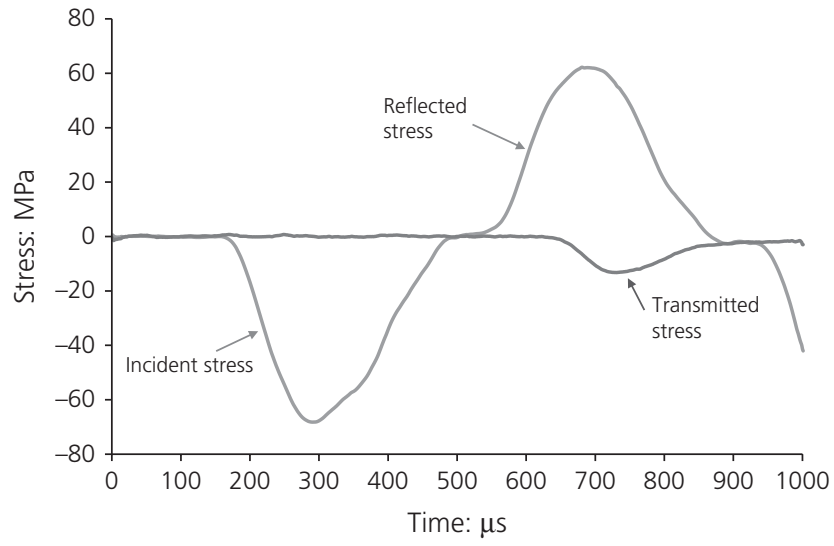

(a)

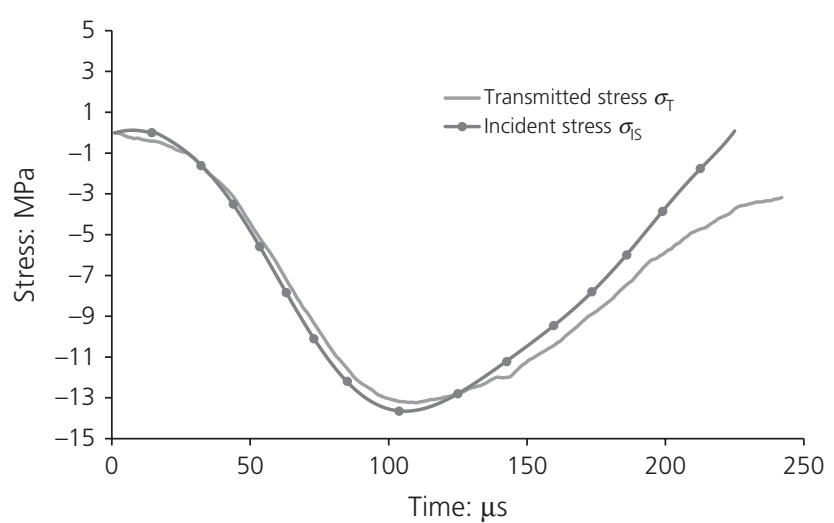

(b)

Figure 7. (a) Typical stress histories in SHPB tests. (b) Comparison of stresses at incident and transmitted ends of specimen

\section{Comparison of failure processes and modes}

With the assistance of a high-speed camera, the failure processes of specimens under dynamic splitting tension were recorded for detailed investigation. Figure 8 compares the failure processes of plain concrete and $0 \cdot 5 \%$ SFRC specimens under a similar stress rate of around $150 \mathrm{GPa} / \mathrm{s}$. The initial image was chosen as the reference for comparison in this study, and the time instant that the specimen started to be stressed was set to zero. The high-speed camera had to sacrifice resolution to reach a higher frame rate, and therefore the illustrative snapshots are only $192 \times 192$ pixels. Image analysis by means of counting the pixel numbers between top and bottom points (points $\mathrm{A}$ and $\mathrm{B}$ as indicated in Figure 8 ) was conducted at different time instants to estimate the crack opening displacement (COD) given in each photo. The number of pixels between points $\mathrm{A}$ and $\mathrm{B}$ before the specimen was stressed was set as the reference, representing the diameter of the specimen, namely $L_{\mathrm{AB}}=75 \mathrm{~mm}$. Due to the limitation of the high-speed camera, the resolution of the image analysis results was only $0.48-0.51 \mathrm{~mm}$ for different specimens. In other words, the COD could only be very roughly estimated as integral multiplication of around $0.5 \mathrm{~mm}$ in Figure 8 and Figure 9.

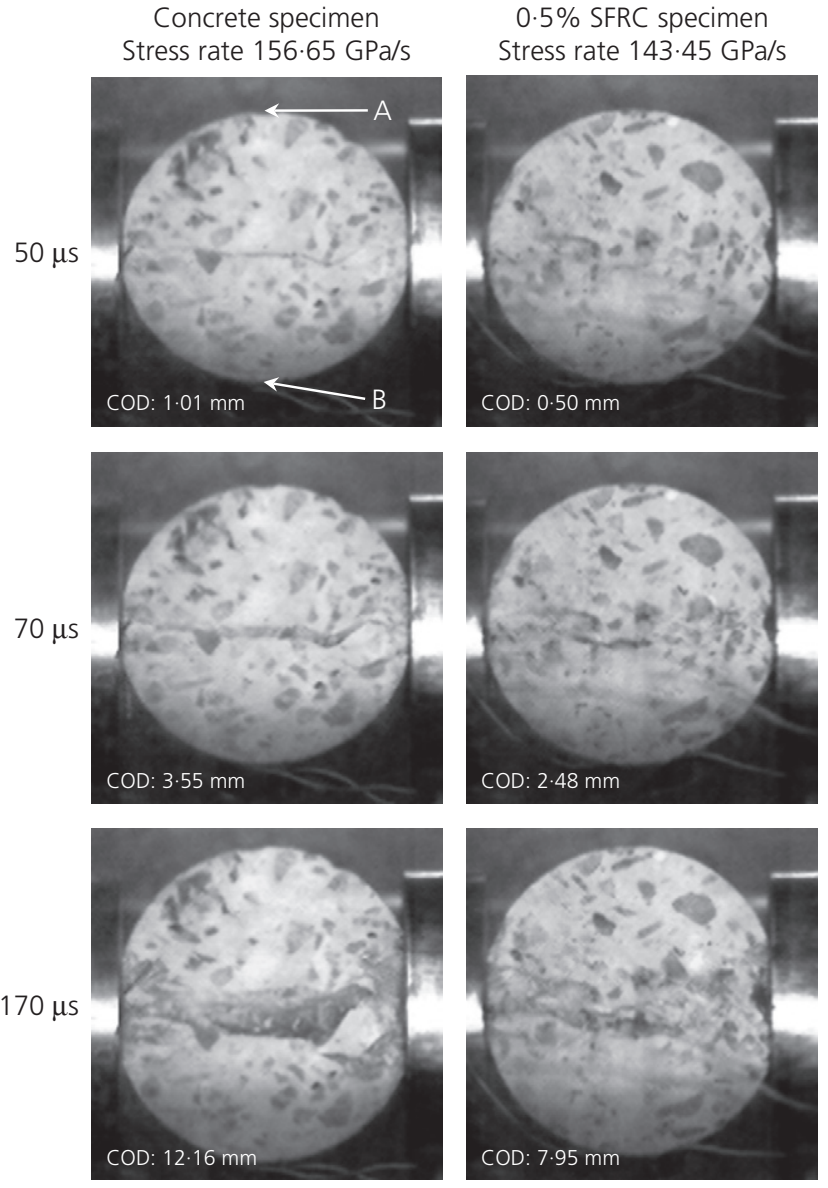

Figure 8. Comparison of failure processes of concrete and 0.5\% SFRC specimens under a stress rate around $150 \mathrm{GPa} / \mathrm{s}$

Figure 8 shows that, at $50 \mu \mathrm{s}$, major cracks had developed in both specimens. At $170 \mu \mathrm{s}$, both specimens were completely split into two halves. Regarding the COD development over time, it was found that the width of the crack in the $0.5 \%$ SFRC specimen was $4.21 \mathrm{~mm}$ smaller than that in the plain concrete specimen at $170 \mu \mathrm{s}$, indicating that the $0.5 \%$ fibre addition effectively reduced the crack opening velocity.

The failure processes of the $1.0 \%$ and $1.5 \%$ SFRC specimens under a stress rate of about $150 \mathrm{GPa} / \mathrm{s}$ are shown in Figure 9: they are significantly different from the failure processes of the specimens shown in Figure 8. At the instant of crack initiation, the COD in the $1.5 \%$ SFRC specimen was $0.49 \mathrm{~mm}$ less than that in the $1.0 \%$ SFRC specimen, indicating a smaller crack opening velocity. It is interesting to note that, at $130 \mu \mathrm{s}$, the CODs in the two specimens reduced by 0.49 and $0.48 \mathrm{~mm}$, respectively, as compared with those at $90 \mu \mathrm{s}$, indicating that the spiral fibres actually partially recovered crack opening in the two specimens. At $170 \mu \mathrm{s}$, a second crack across the aggregate was formed in the $1.0 \%$ SFRC specimen, whereas the second crack in the $1.5 \%$ SFRC specimen did not form until 
Mechanical properties and behaviour of concrete reinforced with spiral-shaped steel fibres under dynamic splitting tension

$\mathrm{HaO}$ and HaO
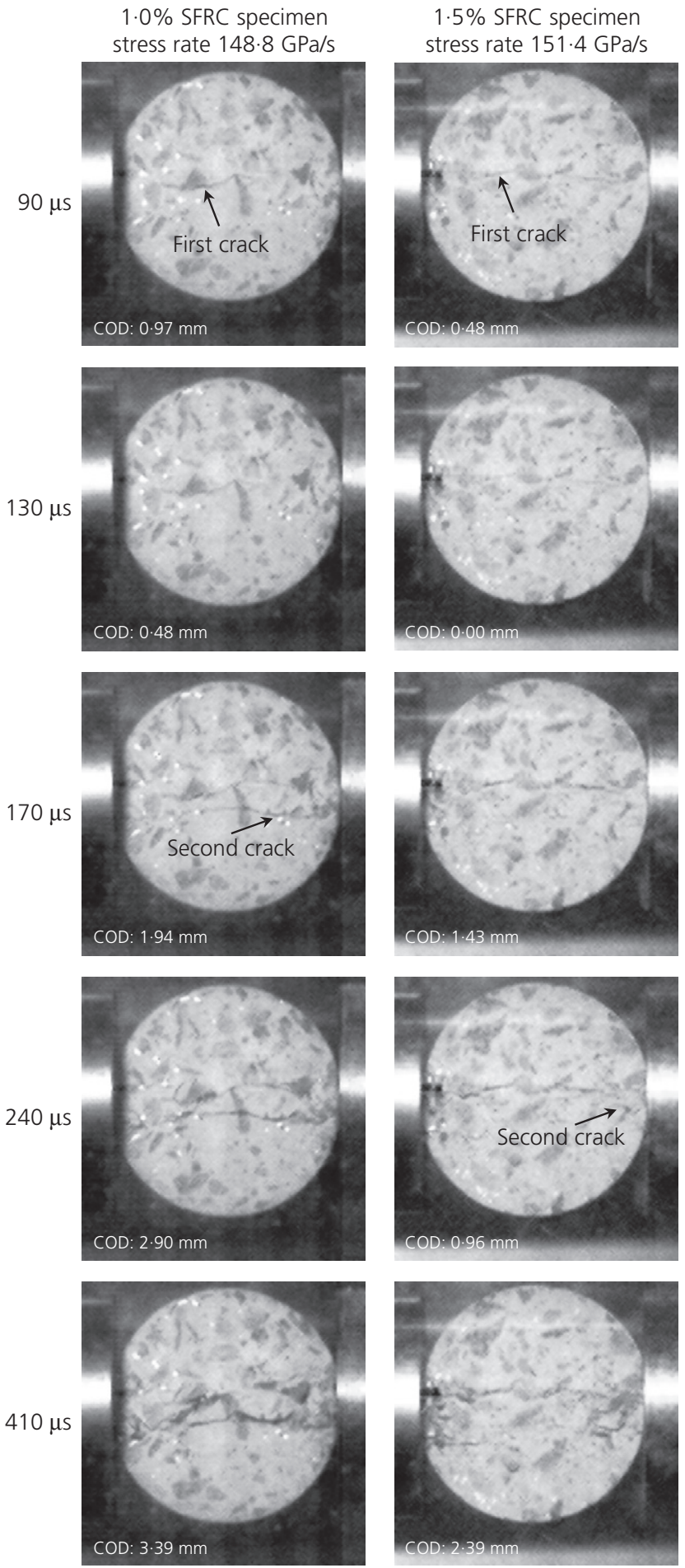

Figure 9. Comparison of failure processes of $1.0 \%$ and $1.5 \%$ SFRC specimens under a stress rate around $150 \mathrm{GPa} / \mathrm{s}$

$240 \mu \mathrm{s}$, indicating that the increased fibre content slowed crack development under splitting tension. Compared with the COD in the plain concrete specimen of $12.16 \mathrm{~mm}$ at $170 \mu \mathrm{s}$, the reductions of $\mathrm{COD}$ in the $0.5 \%, 1.0 \%$ and $1.5 \%$ SFRC

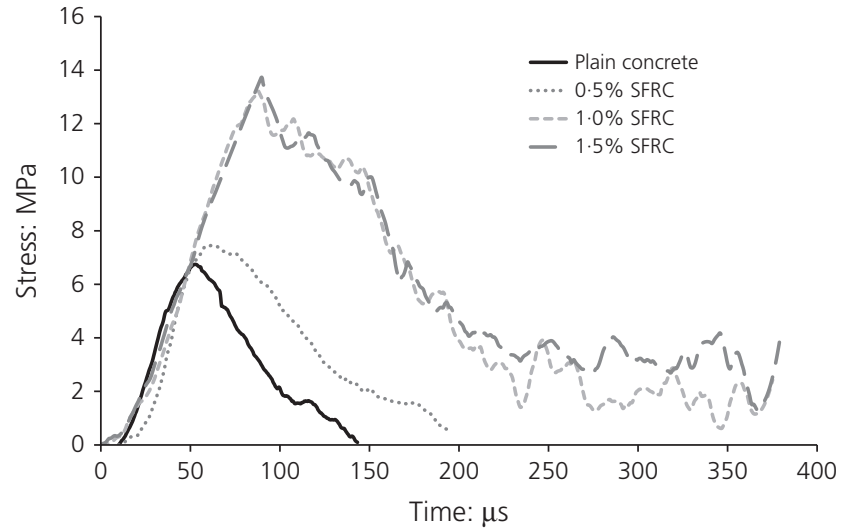

Figure 10. Loading histories of plain concrete and $0.5 \%, 1.0 \%$ and $1.5 \%$ SFRC specimens

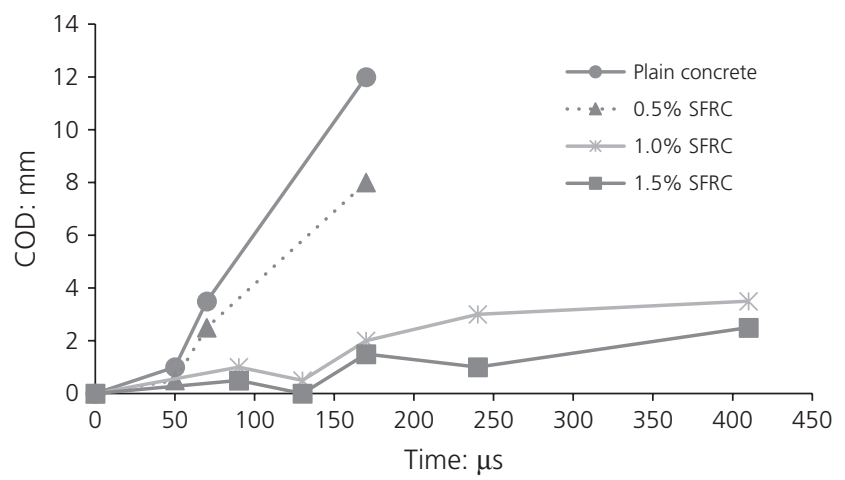

Figure 11. Comparison of CODs under a stress rate of around $150 \mathrm{GPa} / \mathrm{s}$

specimens were $35 \%, 76 \%$ and $92 \%$, respectively. The corresponding loading histories and a comparison of crack width histories for all the specimens are given in Figure 10 and Figure 11, respectively.

Figure 12 shows typical damaged specimens after testing. As shown in the figure, under a splitting stress rate of around $150 \mathrm{GPa} / \mathrm{s}$, the failure patterns of the plain concrete and $0.5 \%$ SFRC specimens showed no apparent difference except that the spiral fibres were exposed along the crack, indicating fibre pull-out. With an increase in fibre volume fraction, it can be seen that the spiral fibres in the $1.0 \%$ SFRC specimen (Figure 12(c)) were still able to hold the split halves together, and the split parts of the $1.5 \%$ SFRC specimen (Figure 12(d)) after impact were held even more firmly by the spiral fibres; no fibre pull-out or fibre fracture was observed in these specimens. This again demonstrates the excellent capability of spiralshaped fibres in maintaining the structural integrity of SFRC material. 
Mechanical properties and behaviour of concrete reinforced with spiral-shaped steel fibres under dynamic splitting

$\mathrm{HaO}$ and Hao

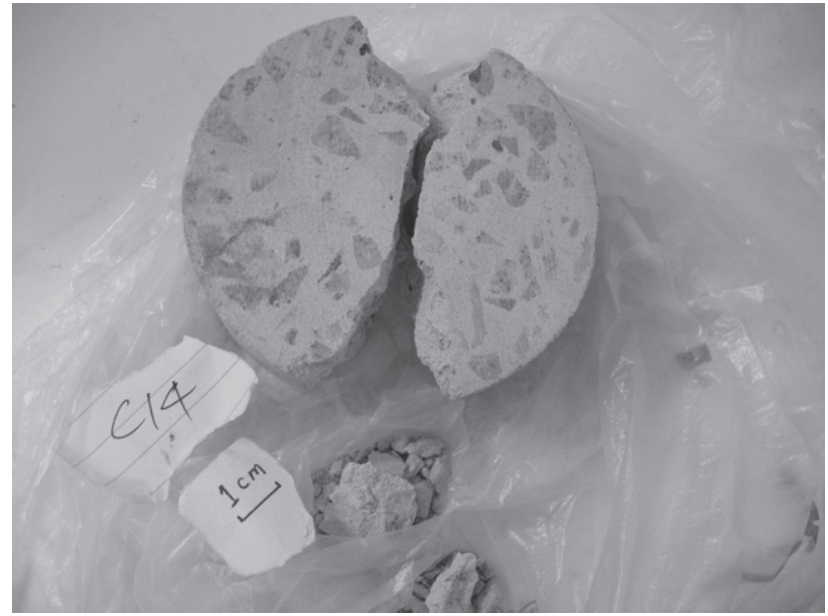

(a)

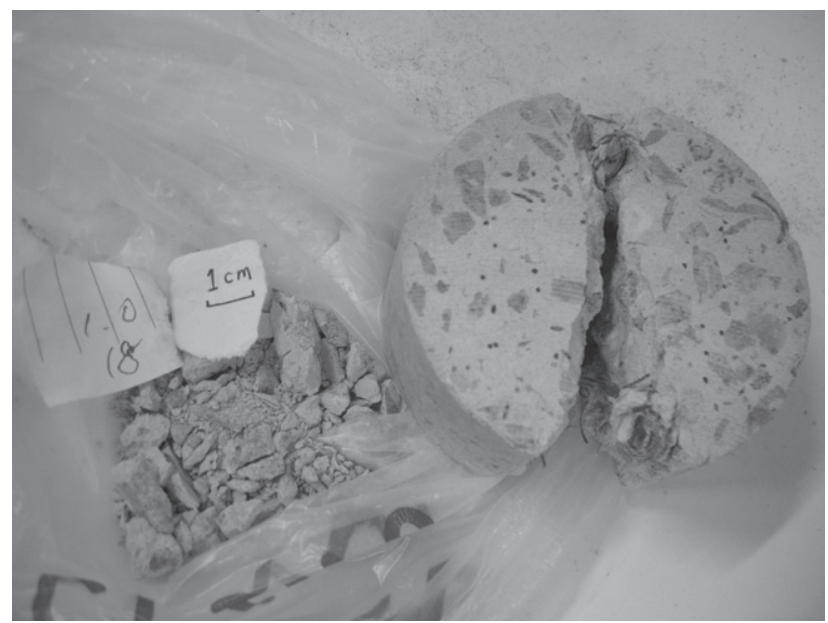

(c)

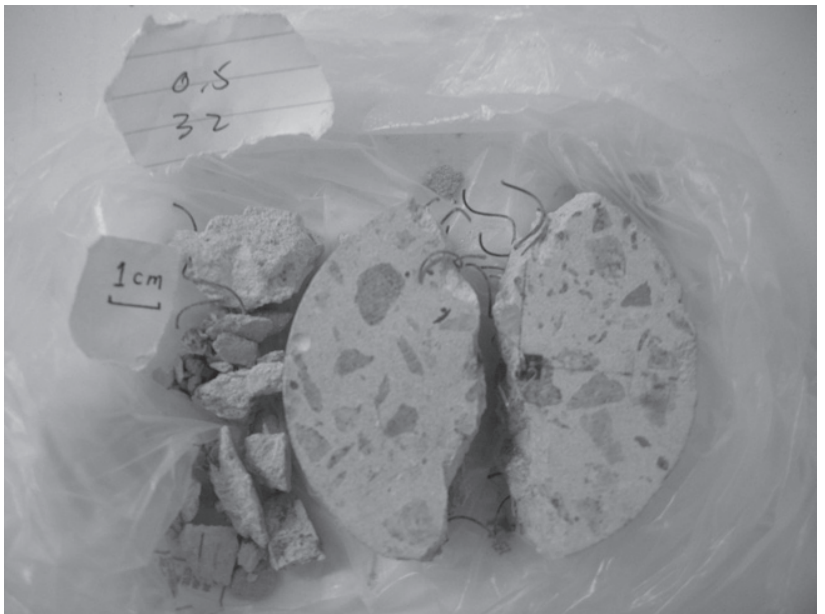

(b)

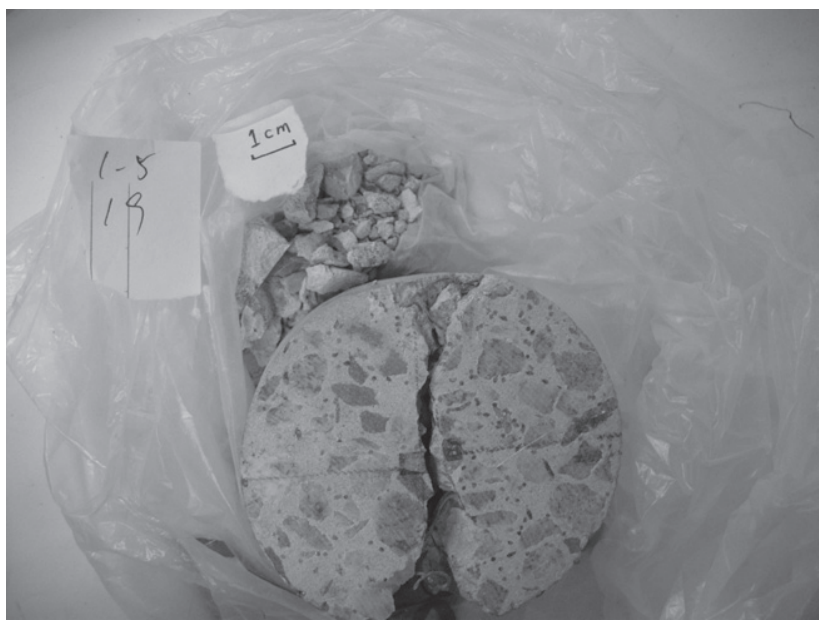

(d)

Figure 12. Comparison of failure patterns under a stress rate of around $150 \mathrm{GPa} / \mathrm{s}$ : (a) plain concrete; (b) $0.5 \%$ SFRC; (c) $1.0 \%$ SFRC; (d) $1.5 \%$ SFRC

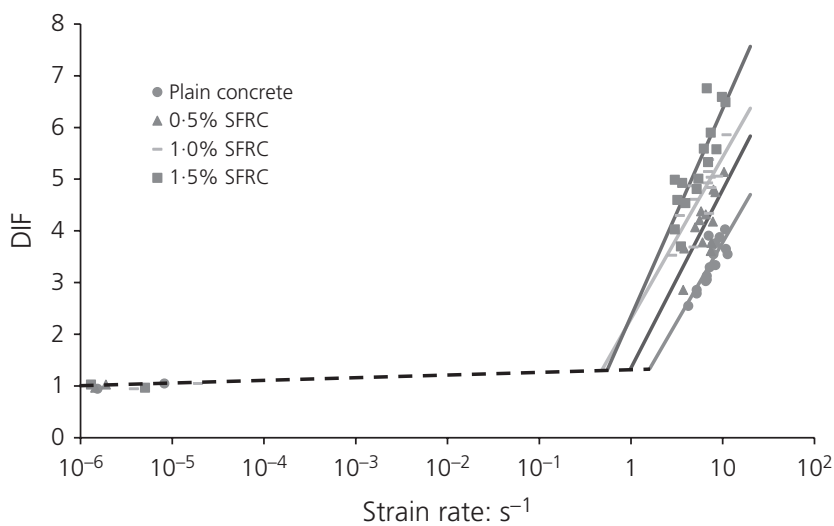

Figure 13. DIFs and best-fit curves

\section{Discussion on dynamic increase factors}

The DIFs with respect to strain rate obtained from the SHPB tests are plotted in Figure 13. The general tendency of the DIF data is clear - the strain rate sensitivity of plain concrete was the least among the materials tested, and increased with fibre content of the spiral fibre reinforced concrete specimens. The concrete mixture with $1 \cdot 5 \%$ fibre addition showed the most significant rate sensitivity. It has been suggested in available experimental and analytical studies that there is a direct relation between the tensile behaviour of SFRC and the pull-out behaviour of single fibres from a concrete matrix. It is believed that general fibre pull-out is integrated with the contribution of each fibre to the corresponding tensile resistance of SFRC. For instance, it has been reported that changing the loading rate would result in changing the maximum pull-out load, the pullout energy and the failure mode (Banthia and Trottier, 1991). Several factors are considered to primarily affect the pull-out 
Magazine of Concrete Research

Volume 68 Issue 21
Mechanical properties and behaviour of concrete reinforced with spiral-shaped steel fibres under dynamic splitting tension

$\mathrm{HaO}$ and $\mathrm{HaO}$

\begin{tabular}{cccc} 
Plain concrete & $0.5 \%$ SFRC & $1.0 \%$ SFRC & $1.5 \%$ SFRC \\
\hline 0.8284 & 0.7405 & 0.8109 & 0.8392
\end{tabular}

Table 5. Correlation coefficients

behaviour, including the matrix strength, the material characteristics of the fibres and especially the fibre-matrix interfacial strength (which governs the adhesive bond strength), frictional resistance to slipping and fibre anchorage capability. Banthia et al. (1994) reported that fibre reinforced concrete composites were found to be stronger and tougher under impact, and this improvement was even more pronounced at higher fibre volume dosages. Therefore, the rate sensitivity of fibre pull-out response and the volumetric fraction of fibres play important roles in the sensitivity of composites to strain rate, which explains the different DIF behaviours of specimens with different fibre volume fractions in the present study.

Researchers tend to agree that there is a linear relation between DIF and logarithmic strain rate for strain rates smaller than $1-2 \mathrm{~s}^{-1}$. When the strain rate exceeds this threshold, a sharp increase in DIF is normally observed. Besides the linear relation for strain rates less than $1-2 \mathrm{~s}^{-1}$, popular ways to quantify the sharply increasing DIF with respect to strain rate $\left(\geq 1-2 \mathrm{~s}^{-1}\right)$ include linear (Tedesco and Ross, 1998), bi-linear (Hao and Hao, 2014), higher-order polynomial (Hao et al., 2012) and power law (Malvar and Ross, 1998) relationships. The present study uses the relatively simple but most commonly used linear relation for quantifying DIF data at strain rates higher than $2 \mathrm{~s}^{-1}$. Based on all available test data obtained in the present study, the best-fit curves for DIFs of the different materials with respect to the logarithmic value of strain rate are given in Figure 13, while the correlation coefficients are listed in Table 5. The fitted formulae for DIF versus strain rates between $2 \mathrm{~s}^{-1}$ and $20 \mathrm{~s}^{-1}$ in Figure 13 are

7. TDIF $_{\mathrm{C}}=3.0701 \log \dot{\varepsilon}+0.7085$ for $2 \mathrm{~s}^{-1} \leq \dot{\varepsilon} \leq 20 \mathrm{~s}^{-1}$

8. $\mathrm{TDIF}_{0.5 \%}=3.4471 \log \dot{\varepsilon}+1.3493$ for $2 \mathrm{~s}^{-1} \leq \dot{\varepsilon} \leq 20 \mathrm{~s}^{-1}$

9. $\mathrm{TDIF}_{1.0 \%}=3.1296 \log \dot{\varepsilon}+2.2996$ for $2 \mathrm{~s}^{-1} \leq \dot{\varepsilon} \leq 20 \mathrm{~s}^{-1}$

10. $\operatorname{TDIF}_{1.5 \%}=4.0106 \log \dot{\varepsilon}+2.3491$ for $2 \mathrm{~s}^{-1} \leq \dot{\varepsilon} \leq 20 \mathrm{~s}^{-1}$ where TDIF represents the dynamic increase factor for tensile strength, and the subscripts $\mathrm{C}, 0 \cdot 5 \%, 1 \cdot 0 \%$, and $1 \cdot 5 \%$ represent specimens made of plain concrete and $0 \cdot 5 \%, 1 \cdot 0 \%$ and $1.5 \%$ SFRC, respectively.

\section{Concluding remarks}

This paper extends an experimental study of spiral-shaped steel fibre reinforced concrete (SFRC) specimens under impact loads considering different volume fractions of fibres. Using a high-speed camera, the crack opening and closing processes of SFRC specimens under impact loading were observed. The images obtained demonstrate the outstanding performance of spiral-shaped fibres in controlling crack propagation and maintaining the structural integrity of SFRC under high-speed impact loads. Based on the results from laboratory tests, the main findings in this study can be summarised as follows.

- Under quasi-static loadings, adding spiral fibres to a concrete mixture improved the splitting tensile strengths. The addition of $1.5 \%$ spiral fibres improved the splitting tensile strength by almost $50 \%$. It was found that fibres in the post-cracking stage were able to maintain the integrity of the specimen, thus forming a load-transfer system to continuously resist the applied load, which resulted in a significantly improved energy absorption capacity.

- A comparison of the failure processes and failure patterns from high-speed camera images demonstrated the excellent bonding of spiral fibres to the concrete matrix. The split halves of the specimens continued to resist load and dissipate energy due to the maintained integrity. Image analysis demonstrated that, at the same time instant, the crack opening displacement in an SFRC specimen dosed with $1.5 \%$ spiral fibres could be as small as $8 \%$ of that of a plain concrete specimen. The ability to maintain the integrity and thus the energy absorption capacity of SFRC specimens was improved with an increase in fibre content.

- Dynamic increase factor (DIF) data were derived from laboratory test results. A comparison of DIFs for tensile strength showed that the rate sensitivity of cementitious materials investigated in the present study increased with fibre content. The DIF versus strain rate relations were described by empirical formulae.

\section{Acknowledgements}

The authors acknowledge the Australian Research Council (grant number DP130104332) and the China National Natural Science Foundation (grant number 51227006) for financial support to carry out this study.

\section{REFERENCES}

Abadel A, Abbas $\mathrm{H}$, Almusallam T, Al-Salloum $\mathrm{Y}$ and Siddiqui $\mathrm{N}$ (2015) Mechanical properties of hybrid fibre-reinforced concrete - analytical modelling and experimental 
behaviour. Magazine of Concrete Research 68(16): 823-843, http://dx.doi.org/10.1680/jmacr.15.00276.

Alwan JM, Naaman AE and Guerrero P (1999) Effect of mechanical clamping on the pull-out response of hooked steel fibers embedded in cementitious matrices. Concrete Science and Engineering 1(1): 15-25.

ASTM (2006) ASTM C1609/C1609M-05: C1609: Standard test method for flexural performance of fiber reinforced concrete (using beam with third-point loading). ASTM, West Conshohocken, PA, USA.

ASTM (2011) C496: Standard test method for splitting tensile strength of cylindrical concrete specimens. ASTM, West Conshohocken, PA, USA.

Banthia N and Trottier JF (1991) Deformed steel fibercementitious matrix bond under impact. Cement and Concrete Research 21(1): 158-168.

Banthia N, Chokri K, Ohama Y and Mindess S (1994) Fiberreinforced cement based composites under tensile impact. Advanced Cement Based Materials 1(3): 131-141.

Bischoff P and Perry S (1991) Compressive behaviour of concrete at high strain rates. Materials and Structures 24(6): 425-450.

Brandt AM (2008) Fibre reinforced cement-based (FRC) composites after over 40 years of development in building and civil engineering. Composite Structures 86(1-3): 3-9.

Cotsovos D and Pavlović M (2008) Numerical investigation of concrete subjected to high rates of uniaxial tensile loading. International Journal of Impact Engineering 35(5): 319-335.

Davies J and Bose D (1968) Stress distribution in splitting tests. ACI Journal Proceedings 65(8): 662-669.

Denneman E, Kearsley EP and Visser AT (2011) Splitting tensile test for fibre reinforced concrete. Materials and Structures 44(8): 1441-1449.

Graybeal BA and Baby F (2013) Development of direct tension test method for ultra-high-performance fiber-reinforced concrete. ACI Materials Journal 110(2): 177-186.

Hao Y and Hao H (2013) Dynamic compressive behaviour of spiral steel fibre reinforced concrete in split Hopkinson pressure bar tests. Construction and Building Materials 48: $521-532$.

Hao Y and Hao H (2014) Influence of the concrete DIF model on the numerical predictions of RC wall responses to blast loadings. Engineering Structures 73: 24-38.

Hao Y, Hao H and Zhang X (2012) Numerical analysis of concrete material properties at high strain rate under direct tension. International Journal of Impact Engineering 39(1): 51-62.

Hao Y, Hao H, Jiang G and Zhou Y (2013) Experimental confirmation of some factors influencing dynamic concrete compressive strengths in high-speed impact tests. Cement and Concrete Research 52: 63-70.

Hao Y, Hao H and Chen G (2016) Experimental investigation of the behaviour of spiral steel fibre reinforced concrete beams subjected to drop-weight impact loads. Materials and Structures 49(1): 353-370.
Kim DJ, El-Tawil S and Naaman AE (2009) Rate-dependent tensile behavior of high performance fiber reinforced cementitious composites. Materials and Structures 42(3): 399-414.

Kupfer H, Hilsdorf HK and Rusch H (1969) Behavior of concrete under biaxial stresses. ACI Journal Proceedings 66(8): 656-666.

Laranjeira F, Aguado A and Molins C (2010a) Predicting the pullout response of inclined straight steel fibers. Materials and Structures 43(6): 875-895.

Laranjeira F, Molins C and Aguado A (2010b) Predicting the pullout response of inclined hooked steel fibers. Cement and Concrete Research 40(10): 1471-1487.

Lok T and Zhao P (2004) Impact response of steel fiber-reinforced concrete using a split Hopkinson pressure bar. Journal of Materials in Civil Engineering 16(1): $54-59$.

Lok T, Li X, Liu DS and Zhao P (2002) Testing and response of large diameter brittle materials subjected to high strain rate. Journal of Materials in Civil Engineering 14(3): 262-269.

Malvar LJ and Ross CA (1998) Review of strain rate effects for concrete in tension. ACI Materials Journal 95(6): 735-739.

Naaman AE and Najm H (1991) Bond-slip mechanisms of steel fibers in concrete. ACI Materials Journal 88(2): 135-145.

Naaman AE and Shah SP (1976) Pull-out mechanism in steel fiber-reinforced concrete. Journal of the Structural Division ASCE 102: 1537-1548.

Naaman AE, Namur GG, Alwan JM and Najm HS (1991) Fiber pullout and bond slip. I: analytical study. Journal of Structural Engineering 117(9): 2769-2790.

Robins P, Austin S and Jones P (2002) Pull-out behaviour of hooked steel fibres. Materials and Structures 35(7): 434-442.

Ross CA, Tedesco JW and Kuennen ST (1995) Effects of strain rate on concrete strength. ACI Materials Journal 92(1): 37-47.

Shah SP, Daniel Jl, Ahmad SH et al. (1993) Guide for specifying, proportioning, mixing, placing, and finishing steel fiber reinforced concrete. ACI Materials Journal 90(1): 94-101.

Swaddiwudhipong S, Lu HR and Wee TH (2003) Direct tension test and tensile strain capacity of concrete at early age. Cement and Concrete Research 33(12): 2077-2084.

Taerwe L and Matthys S (2013) Fib Model Code for Concrete Structures 2010. Ernst \& Sohn, Wiley, Berlin, Germany.

Tang T (1994) Effects of load-distributed width on split tension on unnotched and notched cylindrical specimens. Journal of Testing and Evaluation 22(5): 401-409.

Tedesco J and Ross C (1998) Strain-rate-dependent constitutive equations for concrete. Journal of Pressure Vessel Technology 120(4): 398-405. 
Tedesco JW and Ross CA (1993) Experimental and numerical analysis of high strain rate splitting-tensile tests. $A C I$ Materials Journal 90(2): 162-169.

Xu Z, Hao H and Li H (2012a) Dynamic tensile behaviour of fibre reinforced concrete with spiral fibres. Materials \& Design 42: 72-88.

Xu Z, Hao H and Li H (2012b) Experimental study of dynamic compressive properties of fibre reinforced concrete material with different fibres. Materials \& Design 33: $42-55$.
Yoo DY, Shin HO, Lee JY and Yoon YS (2015) Enhancing cracking resistance of ultra-high-performance concrete slabs using steel fibres. Magazine of Concrete Research 67(10): 487-495, http://dx.doi.org/10.1680/macr. 14.00116.

Zheng W, Kwan A and Lee P (2001) Direct tension test of concrete. ACI Materials Journal 98(1): 63-71.

Zìle E and Zīle O (2013) Effect of the fiber geometry on the pullout response of mechanically deformed steel fibers. Cement and Concrete Research 44: 18-24.

\section{HOW CAN YOU CONTRIBUTE?}

To discuss this paper, please submit up to 500 words to the editor at journals@ice.org.uk. Your contribution will be forwarded to the author(s) for a reply and, if considered appropriate by the editorial board, it will be published as a discussion in a future issue of the journal. 